\title{
Myths about autism: an exploratory study using focus groups
}

Article

Accepted Version

John, R. P. S., Knott, F. J. and Harvey, K. N. (2018) Myths about autism: an exploratory study using focus groups. Autism, 22 (7). pp. 845-854. ISSN 1362-3613 doi:

https://doi.org/10.1177/1362361317714990 Available at https://centaur.reading.ac.uk/70616/

It is advisable to refer to the publisher's version if you intend to cite from the work. See Guidance on citing.

To link to this article DOI: http://dx.doi.org/10.1177/1362361317714990

Publisher: Sage

All outputs in CentAUR are protected by Intellectual Property Rights law, including copyright law. Copyright and IPR is retained by the creators or other copyright holders. Terms and conditions for use of this material are defined in the End User Agreement.

\section{www.reading.ac.uk/centaur}

\section{CentAUR}

Central Archive at the University of Reading

Reading's research outputs online 
Myths about autism: An exploratory study using focus groups

Rachael PS John ${ }^{1}$, Fiona J Knott ${ }^{2}$ and Kate N Harvey ${ }^{2}$

\title{
Affiliations:
}

${ }^{1}$ Ealing Community Team for People with Learning Disabilities, UK

${ }^{2}$ University of Reading, School of Psychology and Clinical Language Sciences, Reading, UK

\section{Corresponding author}

Fiona Knott, School of Psychology and Clinical Language Sciences, University of Reading, Harry Pitt Building, Earley Gate, Reading RG6 7BE

Email; f.j.knott@reading.ac.uk

Tel: 01183787539

\section{Myths about Autism: An exploratory study using Focus Groups}

\begin{abstract}
Individuals with autism are often stigmatised and isolated by their typically developing peers according to parental, teacher and self-reports. Whilst quantitative studies often report negative attitudes towards individuals with autism, it is still unclear how understandings of autism influence attitudes. In this exploratory study, misconceptions or myths about autism, i.e. the cognitive component of attitudes, were examined using focus groups.
\end{abstract}

Purposive sampling was used to recruit undergraduate and postgraduate students, and adults with and without experience of autism, to one of five focus groups ( $n=37$ ). Content analysis was used to identify emergent themes. The data identified seven 
commonly held beliefs about individuals with autism. The first four were related to social interaction, such as that people with autism do not like to be touched. The fifth reflected the view that all individuals with autism have a special talent and the final two concerned beliefs that people with autism are dangerous.

The findings from this study demonstrate that people with varying experience or knowledge of autism often hold inaccurate beliefs about autism. These findings improve our understandings of lay-beliefs about autism, and will aid the development and implementation of interventions designed to improve lay-knowledge of autism.

\section{Keywords}

Autism, public attitudes, myths, beliefs, focus group

\section{Funding}

This research received no specific grant from any funding agency in the public, commercial, or notfor-profit sectors. 


\section{Introduction}

Individuals with autism ${ }^{1}$ experience difficulties with social interaction and communication and have restricted or repetitive stereotyped patterns of behaviours and interest (American Psychological Association, 2013). Although autistic people are often interested in forming relationships (Rowley, 2012) their social communication challenges may result in problematic social interactions with neurotypical individuals (Church et al., 2000, Haq and Le Couteur, 2004 and Masteen, 2011) and negative social experiences including loneliness, bullying, shunning and stigmatization are common (Cappadocia and Weiss, 2011 and Roekel, Scholte and Didden 2010). However, there is a paucity of research exploring the origins and consequences of stigmatized views of populations with autism, hindering the development of targeted, high quality public awareness and education campaigns. The current qualitative study therefore examines the beliefs and misconceptions about autism held by a lay-population that included participants who had varying knowledge and experience of individuals with autistic spectrum conditions.

Stigma involves holding and acting on prejudicial attitudes and beliefs that are based upon pre-conceived ideas held by a dominant group, such as typically developing peers towards an 'out group', for example autistic individuals (Corrigan and Watson 2002). Being subject to stigma and discriminatory behaviour can adversely affect mood and emotional wellbeing (Smith et at 2011) and lead to other negative outcomes such as reduced access to health care (Earnshaw and Quinn 2012). Whilst an extensive amount of research has indicated that individuals with mental illness experience stigma, (Angermayer and Dietrich, 2006, Corrigan, 2002, and Ellison, Mason and Scior, 2013) the experience of stigma by

\footnotetext{
${ }^{1}$ We use the term 'autism' to refer to the autism spectrum, including Asperger syndrome. Consistent with preferences of people with autism and professionals (Kenny, et al 2015) we use the terms 'autistic individuals' individuals with autism' interchangeably.
} 
individuals with autism and their families has been largely neglected (Kinnear et al 2016). This is despite recognition that that stigmatizing experiences are frequent and that families of autistic children may even be more stigmatized than families of children with other disabilities (Broady et al 2015). For instance, Gray (1993 and 2002) found that parents of verbally able children with autism felt stigmatized by members of the general public, describing that they felt judged when their child presented with behaviors associated with autism. Similarly, parents in Broady et al's (2015) study reported the stigmatizing impact of lack of knowledge about autism, reporting feeling judged and rejected by family and friends. Adults and adolescents with autism also report feeling stigmatised and victimized by their peers during social encounters (Shtayemman, 2009). Using self-report and web-based questionnaires it was found that individuals with Asperger syndrome experienced victimization in various domains but with particularly high scores in overt (physical harm and threat) and relational (exposure to behaviours aimed at damaging individuals relationships) domains. Levels of stigma were negatively correlated with severity of autism symptoms.

Whilst these studies provide evidence that autistic individuals are stigmatized and experience negative social encounters, there is currently very little understanding of the factors or perceptions that may underlie this stigmatizing behavior (Jensen et al 2016). Recent studies in the USA (Mitchell and Locke 2015) and Northern Ireland (Dillenberger, McKerr, Jordan et al 2013) showed that the general public were aware of autism, and have some accurate knowledge about the cause of autism, and the existence of helpful interventions, though confusion and inaccuracies were still apparent. Self-reported attitudes to people with autism were mixed. Similarly, Jensen and colleagues (2016) found that the general population in Denmark recognized core symptoms and supported ideas about biological cause. Negative stereotypes about autism were associated with lower levels of 
willingness to interact with people with autism. Butler (2011) used a student sample to investigate stigmatizing views about individuals with Asperger Syndrome, in particular whether behaviors of AS or the label AS elicited stigmatization. The findings showed that college students' attitudes were negatively affected by the description of the social behaviors associated with AS rather than the label of AS. Similarly, autistic children are often perceived negatively by their typically developing peers and self-report shows that their behavioral intentions towards children with autism are less positive than to both typically developing peers and peers with other disabilities (Campbell, et al 2004; Swaim and Morgan, 2001). However, research studies typically use questionnaires and pre-selected adjectives to assess attitudes, which do not allow the origins of beliefs and attitudes to be identified.

Draisma (2009) argues that portrayals of autism in the media (novels, television, films and autobiographies) have built up misrepresentations of autism, for instance suggesting that individuals with autism possess savant skills (extraordinary abilities in a specific area despite poorer functioning). In fact only a very small proportion of autistic individuals possess such skills (Howlin, 2009, Jarrett 2014), but these representations can lead to unrealistic expectancies of the abilities of individuals with autism. It has been long recognized that autism is subject to misconception, which researchers have commonly characterised as "myth" because of the inaccurate basis of the belief; either it is not supported by evidence, or because it is inappropriately applied to all people with autism (e.g. Wing 1997, Jarrett 2014). This characterisation extends beyond research, for example leading charities such as the UK's National Autistic Society include pages on their website explicitly challenging such myths. Beliefs about savant skills are one such misrepresentation 
or myth associated with autism, and raise the possibility that there are other possible misrepresentations of autism that have yet to be revealed.

Exploring commonly held myths about autism may provide a window into the types of beliefs that are held by lay-people. Myths are inaccurate stories or narratives about a group (Corrigan et al 2002; Csiernik et al 2007), which may contribute to the cognitive component of attitudes (i.e. an individual's belief or understanding about autism). Whilst myths change over time, they provide a basis of beliefs which may influence behavioural intentions towards individuals. Csiernik et al (2007) used a mixed-methods approach, comprising focus groups and questionnaires, to identify four myths regarding the abilities of individuals with mental illness: a) people with mental health issues are all the same; b) people with mental health issues are uneducated therefore unemployable; c) people with mental illness are violent; and d) people with mental illness have no family supports. The authors argue that identifying the misconceptions and myths held by lay-people allow them to be challenged though education and policy (Csiernik et al 2007).

The aim of the current study is to build on previous research by exploring the misconceptions and myths held about people with autism. Identifying these areas will inform improve our understandings of lay-beliefs about autism, and will aid the development and implementation of interventions and campaigns designed to improve layknowledge of autism, with the ultimate goal of improving the quality of life for autistic individuals and their families.

\section{Methods}


Consistent with the aim of understanding complex phenomena that have not previously been explored, a qualitative approach was used (Smith, 2003); specifically a series of focus groups comprising participants from a variety of backgrounds and with varying experience of autism. Focus groups are particularly suited to this aim as the interaction between group members encourages participants to query and explain, allowing their reasoning to emerge (Barbour, 2008). The interactions also enable the extent of consensus and range of diversity to be determined (Barbour, 2008). The study was approved by the (** of ${ }^{* *}$ ) Research Ethics Committee (reference 2012/065/FK).

The research team comprised RJ, an MSc student with training in qualitative methods and experience of working with children and adults with autism; FK, a clinical psychologist and researcher with extensive experience with working with families and children with autism; and $\mathrm{KH}$, a health psychologist with extensive experience of research into mental illness and qualitative methods. The research formed RJ's empirical MSc project. RJ was a student at the ${ }^{* *}$ of $* *$ while the research was conducted (University name removed for anonymity).

\section{Participants}

In a multi-category design, five focus groups were conducted. Participants were eligible if they were aged over 18 years and did not have a diagnosis of autism. Samples were recruited from different populations with the aim of obtaining a diversity of views (Table 1). The final sample included students, older adults and a community sample. The views of younger and older adults were deliberately sought as it was thought their knowledge of, and contact with, people with autism may differ. 
For each focus group an opportunity sample was recruited: undergraduate and postgraduate students at the ${ }^{* *}$ of ${ }^{* *}$; members of the ${ }^{* *}$ of ${ }^{* * \prime}$ s Older Adult Research Panel (a database of adults aged over 50 years who have expressed an interest in participating in research); and members of a church attended by one of the researchers (RJ). In addition, purposive sampling was used to ensure each group contained participants with a range of experiences and knowledge of autism.

In total, 37 participants ( 30 females and 7 males) with a mean age of 36.8 years (range of 18-83 years) were recruited (see table 1). The first focus group (PG) comprised post-graduate Psychology students at the ${ }^{* *}$ of $* *(n=6)$; one participant had experience as a befriender to a person with autism. The second focus group (UG1) comprised nine undergraduate Psychology students at the ${ }^{* *}$ of ${ }^{* *}$, six of whom had current contact with an individual with autism either through employment or a family member. The third focus group (UG2) also comprised undergraduate Psychology students at the ** of**. Of the eight participants, seven reported knowing an individual with autism and two of these reported having contact via employment. The fourth focus group comprised participants from the Older Adults Research Panel $(n=7)(O A)$, only one of whom had experience with children with autism through employment. Finally, participants for the fifth focus group were recruited via a local church $(n=7)(C G)$; three had experience of working with people with autism, and one had social contact with someone with autism. The principle researcher who carried out the focus groups was not acquainted with any of the student participants or the Older Adult Research Panel prior to the study commencement. However, she was a member of the community group and knew three of the seven participants.

\section{Table 1 about here}




\section{Recruitment}

Undergraduate and post-graduate students were recruited via adverts and word-ofmouth. Undergraduate students received an incentive for participating (credit towards a module). Older adults were recruited by the database manager via an advert and participants with known neurological disorders were excluded. For the fifth focus group, the community group, posters were displayed in the church and RJ gave a short talk about the study after a service. Participants then contacted the researcher if they were interested in taking part.

\section{Procedure}

The student and older adult focus groups were conducted at the ${ }^{* *}$ of $* *$, while the community focus group was conducted at a church in West London. RJ moderated each focus group. All participants knew that the research was being conducted for RJ's MSc Dissertation. Written consent for participation was obtained at the start of each focus group.

Each group lasted for approximately an hour (range 45 to 65 minutes) and began with brief introductions (moderator and participants) and an outline of the aims of the research. Participants were reassured that they did not need to have prior experience of, or contact with, someone with autism to participate in discussion. A topic guide, developed by researchers and based on clinical and research expertise, was used to ensure the cognitive and behavioural components of attitudes were explored within a framework that describes attitude as "favourable or unfavourable evaluations that predispose behaviour"(Petty \& Cacioppo, 1986). Participants were encouraged to reflect on what they believed themselves 
and what they had heard about autism through a series of open ended questions. In order to elicit as wide a range of views as possible, participants were invited to think about autism in general and then in relation to more specific settings such as work and the local community. Participants were also encouraged to digress and introduce new topics. During each focus group, the moderator made contemporaneous field notes and spider-diagrams. The spider-diagrams were made visible to participants and used to keep track of the discussions. Towards the end of the group, participants were asked to review and comment on the spider-diagrams. Focus groups were terminated when participants agreed they had nothing further to add. Groups were audio-recorded and transcribed verbatim.

\section{Data Analysis}

Thematic analysis was used, which is a flexible method for identifying, analysing and reporting patterns within data (Braun and Clarke, 2006). The aim of analyses was to identify emergent themes that captured beliefs about autism held across each focus group. The first phase in analyses was familiarisation, when the principal researcher (RJ) replayed and reread transcripts to immerse herself in the data, and discussed initial thoughts and ideas with co-investigators. In the second phase, transcripts were subjected to repeat line by line coding to identify patterns in the data. Specific codes relating to interesting responses about autism were then identified and given particular attention. Codes were of interest if they involved myths, positive and negative attitudes. Phase Three involved searching for themes based on initial coding by combining codes with similar content together. As recommended by Braun et al (2006), a thematic map was developed to aid the generation of themes and enable visualisation of the relationship between themes. Phase Four involved the refinement of themes, subdividing themes into categories, and editing codes. A theme was 
accepted if it had several quotes from the data to support it. Themes judged too diverse were discarded to ensure that themes reflected the whole data. In phase Five, themes were defined and labelled with short phrases that reflected the overall theme. Consideration was given to how themes told an overall story evidenced by the data.

\section{Rigour}

The study was designed to maximise credibility, transferability, dependability and confirmability (Lincoln, 1995). Five groups recruited from diverse backgrounds ensured multiple perspectives were obtained. The moderator sought participant verification by sharing the spider-diagrams towards the end of the focus group, and encouraging comment and reflection. This facilitated a shared-understanding, thus improving the accuracy of the data accuracy (Harper and Cole, 2012). During the data analyses phase, the principal researcher (RJ) had ongoing detailed discussions with her co-investigators (FK \& KH). This process ensured a valid interpretation of the data that did not reflect a single perspective.

\section{Results}

Seven themes about individuals with autism emerged from the focus groups. We decided to term them 'myths' to reflect the fact that the themes reflected widely held misconceptions about autism, or at least about their application to all autistic people. Indeed, there was considerable disagreement between participants in the extent to which these traits were endorsed as characteristic of autism. While none of the themes represent 'truths' about autism, they may be seen as an essential part of the discourse about autism and therefore assist with interpreting lay beliefs about autism. 
The first four myths form an overarching theme about social interaction and social contact, while the remaining three refer to perceived characteristics of people with autism.

The identified myths suggest that all people with autism:

- Myth one: are disinterested in social relationships

- Myth two: do not like to be touched.

- Myth three: are introverts.

- Myth four: are unable to notice social rejection.

- Myth five: have a special talent or savant skill.

- Myth six: are dangerous.

- Myth seven: are mad.

\section{Myths relating to social interaction}

Participants emphasised their understanding that having autism means having difficulties with social interaction, suggesting that this characteristic was both familiar and of interest to participants. However, they debated and were less clear about the factors that might underlie these difficulties, such as lack of social motivation vs lack of social skills.

\section{Myth one: All autistic people are disinterested in social relationships}

Participants in the postgraduate (PG), undergraduate (UG1) older adult focus groups $(\mathrm{OA})$ and the community focus groups who had no experience with autism, expressed uncertainty as to whether people with autism disliked social contact because they were not interested in having social relationships or because they had difficulties with social interactions: 
"Yes, so sometimes you don't know if someone is socially awkward if they have Asperger's or whether they just really don't really like people" Jennifer (PG; no experience with autism)

"Well, they don't seem to show the same interest in forming relationships. I don't know whether that was on the basis of whether they like to or want to. It is harder to determine whether it is or not."

Wendy (PG; no experience with autism)

However, participants in these groups working with children with autism contradicted the belief that people with autism dislike social contact by giving evidence that they enjoy initiating social interactions.

"They can be quite polite as in that they are happy to talk to anyone and acknowledge anyone even the older kids walking through the school, they'll say 'oh hello' and I don't know them at all and they've probably never seen me before where as I suppose it is a child thing."

Shirley (PG; experience with autism)

\section{Myth two: All people with autism dislike being touched}

This theme emerged spontaneously in all focus groups, and there was general agreement that it is a commonly held belief, though some participants expressed uncertainty about its validity. 
"Yes, I was going to say that [agreeing with another participant]. No physical contact."

Tessa (CG; no experience with autism)

One student who had a family member with experience of working children with autism talked about how others perceive autism:

"... how other people might perceive autism reminded me of an anecdote my sibling told me, because she works with young autistic children. She told me of a case about a boy she was looking after. He had obvious autistic symptoms. My sister mentioned it to the boy's mother but the mother was adamant that the boy couldn't be autistic because he liked hugs and the mother's impression was that it could not be possible if he had autism." James (PG; no experience with autism)

Similarly, another participant, also with experience of autism believed that dislike of physical contact is a core feature of autism and indeed suggested that a diagnosis of autism cannot be made when someone likes touch:

"Definitely, I'd say, with this boy he was what we call atypical autism because he loves hugs."

Amy (CG; experience with autism) 
However, an undergraduate student who had experience with autism provided contradictory evidence by recalling a time a person with autism physically embraced her:

"I think they can be easily attached. When I work with the elderly like just this lady I work with part time, and she knows me so when I come there she hugs me."

Amy (UG2; experience with autism)

\section{Myth three: All people with autism are introverts}

In all of the groups, participants considered whether individuals with autism had introverted personalities which may have caused difficulties with social interactions:

Some participants in the community focus group without experience of autism expressed difficulty distinguishing between autism and introverted personality traits, believing they are similar.

"Absolutely, you might have someone who is very shy and withdrawn and somebody might think 'oh they are autistic'." Jackie (CG; no experience with autism)

"I think it is a mild form of autism. Almost sometimes, you know, not even a disorder but a personality. I thought sometime. I don't know." Helen (CG; no experience with autism) 
However, another participant became uncertain about this belief after hearing other participants' responses:

"Well I thought people with autism were more on the withdrawn side but from the two examples we have heard they seem more extraverted." Penny (OA; no experience with autism)

\section{Myth four: All autistic people are unable to notice rejection}

Some participants without prior experience of autism speculated that people with autism are unable to notice rejection.

"My idea is of autism, and I have no prior experience of it or close to, is that they would not notice that if they were isolated or stigmatised and it's interesting because you have to be aware of people's reaction to feel isolated." Helen (OA; no experience with autism)

Another participant who reported no experience with autism was less certain. She recognises there is stigma towards individuals with autism and expressed the hope that as such they are unable to notice this:

"I do wonder if they do pick up, whether it depends on severity, whether they are aware of we were saying. They don't perhaps have a lack empathy so that they don't pick up vibes from other people. In a way, it would be a blessing in disguise 
if they didn't, wouldn't it, you know. I suppose some much negativity there as well as positive."

Jackie (CG; no experience of autism)

"I have certainly met some children in my working life; they haven't been too concerned if they were working on their own. That was a preference they would have sometimes. So if others did not want to work with them it was no big deal really. I guessed it caused less proximity with other people reactions an, they were happy with that."

Penny (OA; experience with autism)

Participants who had contact with someone with autism rejected the belief that individuals with autism are not able to notice social rejection.

An undergraduate student described a situation where his friend who has autism was bullied by peers and was fully aware that others were talking negatively about him:

"I think that some of the things that my friend with Asperger's said ... one time he was going to a meeting at his school and he had bad body odour and he said that a teacher approached him at point blank and told him 'you stink, you need deodorant' ... and he really respected that teacher because everyone else was talking about him behind his back and telling him he stank and stuff and the teacher said it to his face. And he has not had any problems with that teacher." Daniel (UG2; experience with autism) 


\section{Myth five: All people with autism have special talents}

Participants both with and without experience of autism highlighted and recognised exceptional abilities in individuals with autism, but it was apparent that several confused savant skills with more general interests. They provided evidence to support their belief by discussing people with autism who they knew or were aware of and who considered gifted or talented in art, music, languages and computation.

"Well they all seem to be very gifted."

Helen (OA; no experience with autism)

"Well, I work in a computer club for children who have autism for ages eleven to sixteen. Some of them are really good on the computer." Amanda (UG2; experience with autism)

One participant confused a talented guitar playing for a savant skill, assuming that because a person with autism played the guitar he had savant skill for music. Whilst many musicians are able to extemporise, no other evidence is given about the person's abilities that would meet criteria for a savant skill.

"That reminds me of someone else I got ... someone else on confirmation this year who is autistic, um, and on special gifts he is a brilliant key board player. He can play by ear, so that is his special gift." Amy (CG; experience with autism) 
PG participants in the postgraduate without direct experience with autism were aware of the association between autism and special abilities but were uncertain as to whether all people with autism had a particular talent:

"But is it even something related to the disorder? Is it just that they are gifted and it has nothing to do with their autism?" Jennifer (PG; no experience with autism)

"They play this by ear as if it is a different process of music than this kind of thing, but then again I would not think this is generalized to autistic people." Wendy (PG; no experience with autism)

Another postgraduate student without experience with autism believed that media portrayals of gifted abilities in autism may have contributed to the myth that all people with autism possess a talent or gift.

"I think with the specific idea of their being ... there is a special ability concentrated in autistic children ... overlook that the, the, like someone mentioned earlier, it often occurs together with severe learning disabilities and other area. So the popular perception, because of certain books and film, is that autistic children are perceived as gifted but that is a small percentage of gifted children. I don't think it is something that characterises the disorder necessarily." James (PG; no experience with autism) 


\section{Myth six: All autistic people are dangerous}

Across focus groups, many participants held the view that people with autism are feared because their challenging behavior and characteristics are perceived as dangerous. PG, UG1 and UG2 participants shared stories and experiences of people who had contact with individuals with autism and who described them as aggressive.

"I used to live with a guy who was a teaching assistant at a school for autistic children. He was coming home early from school saying 'these children are dangerous' and that it is a dangerous working environment, mainly because if you interrupt their routine .... they would become aggressive. He gave the example of a child who got interrupted and got some scissors and almost stabbed him or something like that."

Susanna (PG; no experience with autism)

One participant with experience with working with children with autism expressed uncertainty about interacting with a person with autism who was similar in age to her, believing they she would be a target of physical aggression. This influenced her uncertainty about having contact with someone with autism:

"I'm not sure about people my age, who may be a bit aggressive, because I haven't had experience before, so I would need to know how to handle it, and obviously if someone is bigger than me and I get punched in the face then that's sort of thing. I would probably want some education about it first." Shirley (UG; experience with autism) 
Similarly, another OA participant who did not have experience of autism rejected social contact with a child with autism perceiving him/her has having the potential to become aggressive.

"I have asked myself if I would be happy to babysit a child with autism. I don't know if I would because I know how their reactions can be and how if they want to do something how strong they can be."

Danny (OA; no experience with autism)

\section{Myth seven: All people with autism are mad}

The data from this study indicates that many participants from all focus groups perceived individuals with autism as "mad". The term "mad" was interpreted by the researchers as mentally unstable, and similar to a mental illness. It suggests individuals with autism are perceived to be mentally ill, perhaps due to uncertainty of the characteristics associated with autism and limited knowledge about autism. Discourses regarding individuals with autism as "mad" came from participants who have heard individuals with autism compared to mentally unstable, unpredictable individuals. Participants also reflected on the way their thinking changed once they had more knowledge of autism.

One participant in the postgraduate focus group recalled hearing others compare Asperger syndrome to being a "psycho", which the researchers interpreted as someone who was mentally ill. 
"I think they think well do they have Asperger's, or are they psycho. I have heard that before somewhere." Jennifer (PG; no experience with autism)

Characteristics of autism were associated with mental illness prior to learning about autism for one undergraduate student. One (UG2) participant reflected on how his understanding of autism and his perception of someone with autism as being "mental" had changed after being taught about autism during psychology lecture.

"It would be easy if you haven't studied autism properly or know about it to assume that they are mental or something. Like before I knew about autism when I was quite young, if I saw someone exhibit some certain symptoms of autism, I would have thought, you know, we would have said to our friends 'that person is mental'. We would not have had time to think about it." John (UG2; no experience with autism)

A CG participant questioned whether an acquaintance she assumed to be mentally ill may have autism:

"This person shouts and shouts all the time ... erm, so she is not, she is not mentally well, but you wouldn't look at her and say she has autism. She could have, she could have had it all of her life." Brandy (CG; experience with autism) 


\section{The importance of education for understanding autism}

The need for education about autism was emphasized by an undergraduate student who admitted to acting with prejudice prior to learning about autism. The following quote suggest behaviors of people with autism are accepted if the observer is aware the person has autism. This suggests that providing information about autism could play a crucial role in reducing prejudice.

"We may have been mean before, and I admit I may have been discriminatory before. Not in a nasty way, but I didn't know anything before, so I would have judged those individuals as before as I didn't know much about it and their personalities, so maybe it's just they need more education. If they did have more experience, well not more experience but more knowledge, but less nastiness." Shirley (UG1; experience with autism)

\section{Discussion}

This study explored the cognitive component of attitudes to gain an understanding of individuals' beliefs about individuals with autism. The findings from this study demonstrate that people with a range of experience and knowledge identified several beliefs about autism but also recognised their uncertainty about the validity of these beliefs. Participants actively reflected about their knowledge and in several cases changed their view after hearing a contribution from a more experienced participant. We chose to conceptualise these themes as 'myths' in order to explore their underlying meaning for participants rather than to engage in debate about the empirical evidence behind any of their ideas. In fact, the range and variation in views realistically reflects the known 
heterogeneity of autism (Masi, et al 2017), in both clinical presentation and genetic underpinnings. However, it was striking that few participants, described autism as a spectrum, or suggested that characteristics may apply to some but not all autistic individuals. Instead they seemed to be searching for a single unified description, at odds with Stephen Shores' well known phrase: 'If you've met one person with autism you've met one person with autism' (Autism Speaks 2013). Establishing misconceptions alongside the poor understanding about the range and variation in the way autism is expressed will highlight areas to be targeted in public awareness campaigns, enhancing awareness and understanding of autism.

The first four myths relate to social interaction: all people with autism are 1) disinterested in social relationships 2) do not like to be touched 3) are introverts and 4) are unable to notice social rejection. The participants' reflections suggested that social interaction, a core feature of autism, is clearly well recognised by a lay population (Jensen et al 2015; Mitchell et al 2015). However, participants in our study also expressed uncertainty about the social interaction abilities of people with autism and these four myths clearly highlight the lack of awareness about the known heterogeneity of autism and its presentation (Constantino and Charman 2016).

The fifth myth, that all individuals with autism have a special talent or savant skill was endorsed by many focus group participants, and was an area of confusion for those remaining. The belief in special talents is a common misconception (Draaisma 2009) with savant skills only occurring in $10 \%$ of people with autism (Treffert, 2009). Draaisma (2009) suggests that believing people with autism have special talents and special abilities may be influenced by films and media portraying people with autism as having savant skills. In the 
current study, participants both with and without experience of autism misinterpreted a general interest as savant skill.

Myths six and seven relate to the beliefs that people with autism are dangerous or mad. In contrast to our findings, some previous surveys have found low levels of endorsement of the myth that people with autism are dangerous (for example, DurandZaleski et al 2012) and show that autism is viewed less negatively than mental health conditions such as schizophrenia (Jensen et al 2015). This inconsistent finding may be a consequence of different methodologies. It is plausible that by providing participants with the opportunity of open discussion, focus groups increase the likelihood that the myth of dangerousness will be acknowledged and expressed. When responding to a survey, on the other hand, participants may reject the myth of dangerousness because they perceive it to be irrational and/or feel subject to social bias. In our study, participants wondered about the myths of dangerousness and madness, and described how they might take care with their behaviour because of 'not knowing'. For instance, some participants expressed uncertainty about wanting contact with someone with autism believing that they might be dangerous or aggressive. Some of these ideas were based on stories they had heard from others who had contact with autistic people, suggesting they had overgeneralised the belief that all people with autism are dangerous. Similarly, many participants discussed the perception that people with autism are 'mad', commenting that unusual behaviours may be wrongly labelled. Participants acknowledged that their own views had changed after attending training, suggesting that lack of awareness may sometimes mean that behaviours are wrongly attributed to mental health problems. However, participants seemed to be searching for an 'either-or' explanation for observed behaviours, rather than recognising the comorbidity of mental health problems and autism (eg Simonoff et al 2008). 
It was clear during the focus groups that participants were engaging in an active process of reflection on their views, which were open to change. There were a number of occasions, for instance, where participants modified their views in the light an account of autism supplied by another member of the group. Two participants also spoke about the way their attitudes and beliefs had changed after attending University lectures about ASD. However, it was also clear that participants were vulnerable to accounts of autism that are inaccurate. Participants talked about the way their views were shaped by media representations of autism through fictional accounts or news items as well as by stories they had heard from friends and family.

\section{Strengths and limitations}

To our knowledge this is one of few studies that have used qualitative methods to explore lay beliefs about autism. Opportunity sampling was used as it facilitates access to participants. It is not the aim of qualitative research to generalise to a population and therefore a representative sample was not sought. However, our participants' characteristics (students; members of an Older Adult Research panel; members of a church) will have shaped their beliefs about autism. Furthermore, while participants were drawn from different age groups and had varying experience of autism, there was limited diversity in ethnicity, with over half of the participants being White-British. Similarly, many participants were educated to at least degree level, though the educational backgrounds of the older adult and community groups were not captured. As often recommended in qualitative studies, further research exploring the beliefs about autism held by other groups with greater ethnic and educational diversity, would build on this study's findings. An additional consideration relating to sampling arises because the principal researcher (RJ) 
attended the church used in the recruitment of the community group. As described earlier, RJ was already acquainted with three of the seven participants. It is accepted that RJ's knowledge and beliefs about the church and its members, and participants' knowledge and beliefs about RJ, will have influenced the data. This was explicitly discussed during the analyses process, when RJ presented her codes to FK and $\mathrm{KH}$ and together they considered the evidence for her interpretations and alternative understandings.

One of the key strengths of the study included recruiting participants who had little experience or knowledge of autism. A second strength was that participants were given explicit permission to talk about views they had heard, rather than only describing their own beliefs. Using focus groups rather than interviews allowed people to explore views, and generated a rich discussion where participants exchanged anecdotes, shared and commented on each other's ideas and experiences. Although the study predominately focused on the cognitive component of attitude, limiting our understanding of the affective or behavioural components, the focus groups allowed us to articulate some of the myths about autism held by a lay-population.

\section{Implications}

This study highlights the role that information can play in attitude formation and change, through media, education and informal contact with those who have experience in ASD. There is good evidence that anti-stigma interventions providing accurate information improves attitudes to mental illness (Corrigan et al 2012) and a recent intervention with students has demonstrated this is also true for attitudes to autism (Gillespie-Lynch et al, 2015). Similarly, contact, whether in person or imagined, also improves attitudes to stigmatised groups such as individuals with mental illness (Corrigan et al 2012). Our first 
four myths suggested that people feel uncertain as to how people with autism may respond during social interactions. Interventions including accurate information and positive contact with people with autism may be an effective way to challenge myths and reduce anxiety about social contact with people with autism.

\section{Conclusion}

Our findings demonstrate that people with varying experience and knowledge of autism hold inaccurate beliefs about autism but are willing to reflect and adapt their views. Identifying myths and views about autism will help with the development of educational based interventions to improve lay understandings of autism.

\section{References}

American Psychiatric Association. (2000). Diagnostic and Statistical Manual of Mental

Disorders: DSM-IV-TR. Washington, DC: American Psychiatric Association.

Angermayer MC and Dietrich S (2006) Public beliefs about and attitudes towards people with mental illness: A review of the population studies. Acta Psychiatrica Scandinvica 113(3): 163-179.

Autism Speaks (2013). Countdown to the Conference: What Will Speaker Dr. Stephen Shore Say? Available at https://www.autismspeaks.org (accessed 19/05/2017).

Barbour, R. (2008) Doing focus groups. London: Sage Publications.

Bogardus, ES (1933) A Social Distance Scale. Sociology and Social Research. 17:265-271.

Braun V and Clarke V (2006) Using thematic analysis in psychology. Qualitative Research in Psychology 3(2): 77-101.

Broady T, Stoyles G and Morse C (2015) Understanding carers' lived experience of stigma: the voice of families with a child on the autism spectrum. Health and Social Care in the Community. doi: 10.1111/hsc. 12297 
Butler, R and Gillis, J (2011) The Impact of Labels and Behaviours on the Stigmatization of Adults with Asperger's Disorder. Journal of Autism and Developmental Disorders 41(6): 741-749.

Campbell JM, Ferguson JE, Herzinger CV, Jackson JN, and Marino, C (2004) Combined descriptive and explanatory information improves peers' perceptions of autism. Research in Developmental Disabilities 25: 321-329.

Cappadocia MC and Weiss JA (2011) Social skills interventions for children and youth with Asperger's syndrome and high functioning autism. Research in Autism Spectrum Disorders 5(1):70-78.

Church C, Alisanski S and Amanullah S (2000) The social, behavioral, and academic experiences of children with Asperger syndrome. Focus on Autism and other Developmental Disabilities 15:12-20.

Contantino J and Charman T (2016) Diagnosis of autism spectrum disorder: reconciling the syndrome, its diverse origins, and variation in expression. The Lancet 15: 27991.

Corrigan PW and Watson AC (2002) Understanding the impact of stigma on people with mental illness. World Psychiatry.1:16 -20.

Corrigan P, Scott MM, Michaels P, Rafacx J and Rusch N (2012) Challenging the Public Stigma of Mental Illness: A Meta-Analysis of Outcome Studies. Psychiatric Services 63(10): 963-973.

Csiernik R , Forchuk C, Speechly, M and Ward-Griffin, C (2007) De "Myth" ifying Mental Health- Findings from a community University Research Alliance (CURA). Critical social Work. 8:1-15.

Dillenburger K, Jordan J, McKern L, Devine P and Keenen M (2013) Awareness and knowledge of autism and autism interventions: A general population survey. Research in Autism Spectrum Disorders, 7(12): 1558-1567 
Draaisma D (2009) Stereotypes of autism. Philosophical Transactions of the Royal London Biological Sciences. 364:1475-1480.

Durand-Zaleski I, Scott J, Rouillon F and Leboyer M (2012) A first national survey of knowledge, attitudes and behaviours towards schizophrenia, bipolar disorders and autism in France. BMC Psychiatry: 212:128

Earnshaw V and Quin D (2012) The Impact of Stigma in Healthcare on People Living with Chronic Illnesses. Journal of Health Psychology, 17(2): 157-168

Ellison N, Mason O and Scior K (2013) Bipolar disorder and stigma: A systematic review of the literature. Journal of Affective Disorders 151(3): 805-820.

Gillespie-Lynch K, Brooks P, Someki F, Obeid R, Shane-Simpson C, Knapp S, Daou N and Shane Smith D (2015) Changing College Students' Conceptions of Autism: An Online Training to Increase Knowledge and Decrease Stigma. Journal of Autism and Developmental Disorders 45(8): 2553-2566.

Gray, DE (1993) Perception of stigma: the parents of autistic Children. Sociology of Health and IIIness. 15(1): 102-120.

Gray, DE (2002) Everybody just freezes. Everybody is just embarrassed': felt and enacted stigma among parents of children with high functioning autism. Sociology of Health and IIIness. 24(6):734-749.

Harper M and Cole P(2012) The Member Checking: Can Benefits Be Gained Similar to Group Therapy. The Qualitative Report. 17(2): 510-517.

Haq I and Le Couteur A (2004) Autism Spectrum Disorder. Medicine 32:61-63.

Howlin P and Frith U (2009) The beautiful otherness of the autistic mind. Philosophical Transactions of the Royal London Biological Sciences. 364, 1345-1350.

Howlin P, Goode S, Hutton J and Rutter M (2009) Savant skills in autism: psychometric approaches and parental reports. Philosophical Transactions of the Royal London Biological Sciences. 364, 1359-1367.

Jarrett C (2014) Autism myth and reality. The Psychologist. 27, 746-749. 
Jensen C, Martens CS, Nikolajsen ND, Skytt -Gregersen T, Heckmann Marx N, Goldberg Frederiksen M and Stene Hansen MS (2015) What do the general population know, believe and feel about individuals with autism and schizophrenia: Results from a comparative survey in Denmark. Autism 20(4): 496-508.

Kenny L, Hattersley C, Molins B, Buckley C, Povey C and Pellicano E. (2015) Which terms should be used to describe autism? Perspectives from the UK autism community. Autism 20 (4): pp. 442-462

Kinnear SH, Link BG, Ballan MS and Fischbach, RL (2016) Understanding the Experience of Stigma for Parents of Children with Autism Spectrum Disorder and the Role Stigma Plays in Families' Lives. Journal of Autism and Developmental Disorders. 46(3): 942-953.

Lincoln YS (1995) Emerging criteria for quality in qualitative and interpretive research. Qualitative Inquiry,1(3): 275-289.

Masi A, DeMayo M, Glozier N and Guastella A (2017 > An overview of autism spectrum disorder, heterogeniety and treatment options. Neuroscience Bulletin, 33 (2): 183-193

Masten CL , Colich NL, Rudie JD, Bookheimer SY, Eisenberger NI and Dapretto M (2011) An $\mathrm{fMRI}$ investigation of responses to peer rejection in adolescents with autism spectrum disorders. Developmental Cognitive Neuroscience 1(3): 260-270.

Mitchell GE and Locke KD (2015) Lay beliefs about autism spectrum disorder among the general public and childcare providers. Autism 19(5) 553-561.

National Autistic Society. Autism facts and history. Available at http://www.autism.org.uk/About/What-is/Myths-facts-stats. (Accessed $3 / 2 / 2017)$

Petty R and Cacioppo J (2012) Communication and persuasion: central and peripheral routes to attitude change. Spring Science and Business Media. 
Roekel VA, Sholte, RHJ and Didden, R (2010) Bullying Among Adolescents With Autism Spectrum Disorders: Prevalence and Perception. Journal of Autism Developmental Disorders 40(1): 63-73.

Rowely E, Chandler S, Baird G, Simonoff E, Pickles A, Loucas T and Charman T(2012) The experience of friendship, victimization and bullying in children with an autism spectrum disorder: Associations with child characteristics and school placement. Research in Autism Spectrum Disorders 6 (3): 1126-1134.

Shtayemman, O (2009) An Exploratory Study of the Stigma Associated With a Diagnosis of Asperger's Syndrome: The Mental Health Impact on the Adolescents and Young Adults Diagnosed With a Disability With a Social Nature. Journal of Human Behaviour in the Social Environment. 19(3). 298-313.

Simonoff E, Pickles A, Charman T, Chandler S, Loucas T and Baird G (2008). Psychiatric Disorders in Children With Autism Spectrum Disorders: Prevalence, Comorbidity, and Associated Factors in a Population-Derived Sample. Journal of the American Academy of Child \& Adolescent Psychiatry 47 (8):921-929.

Smith JA (2003) Qualitative Psychology. A practical guide to Research Methods. London: Sage Publications.

Smith V, Reddy R, Foster K, Asbury ET and Brooks, J (2011) Public perceptions, knowledge and stigma towards people with schizophrenia. Journal of Public Mental Health 10(1): $45-56$.

Swaim KF and Morgan, SB (2001) Children's attitudes and behavioural intentions toward a peer with autistic behaviours: Does a brief educational intervention have an effect? Journal of Autism and Developmental Disorders 31: 195-205.

Treffert DA (2009) The savant syndrome: an extraordinary condition. A synopsis: past, present, future. Philosophical Transactions of the Royal London Biological Sciences. 364: 1351-1357.

Wing L (1997) The history of ideas on autism. Legends, Myths and reality. Autism 1(1):13-23 
Table 1: Characteristics of Focus Group Participants $(n=37)$

\begin{tabular}{|c|c|c|c|c|c|}
\hline $\begin{array}{l}\text { Focus } \\
\text { Group }\end{array}$ & Sample & $\begin{array}{l}\text { Total N } \\
\text { (number } \\
\text { of } \\
\text { women) }\end{array}$ & $\begin{array}{l}\text { Mean Age } \\
\text { (range) }\end{array}$ & Ethnicity & Experience with autism \\
\hline PG & $\begin{array}{l}\text { Post- } \\
\text { graduate } \\
\text { students }\end{array}$ & $\begin{array}{l}6 \\
(5)\end{array}$ & $\begin{array}{l}25 \text { years } \\
(22-30)\end{array}$ & $\begin{array}{l}4 \text { White-British; } \\
1 \text { White- } \\
\text { European; } \\
1 \text { Mixed race Asian } \\
\text { and White }\end{array}$ & $\begin{array}{l}1 \text { via employment (as a } \\
\text { befriender) }\end{array}$ \\
\hline UG1 & $\begin{array}{l}\text { Under- } \\
\text { graduate } \\
\text { students }\end{array}$ & $\begin{array}{l}9 \\
(6)\end{array}$ & $\begin{array}{l}22 \text { years } \\
(18-33)\end{array}$ & $\begin{array}{l}8 \text { White-British; } \\
1 \text { White-European }\end{array}$ & $\begin{array}{l}5 \text { via employment; } \\
1 \text { via family member }\end{array}$ \\
\hline UG2 & $\begin{array}{l}\text { Under- } \\
\text { graduate } \\
\text { students }\end{array}$ & $\begin{array}{l}8 \\
(7)\end{array}$ & $\begin{array}{l}21 \text { years } \\
(19-24)\end{array}$ & $\begin{array}{l}6 \text { White-British; } \\
1 \text { White-Jewish; } \\
1 \text { Black-African }\end{array}$ & $\begin{array}{l}2 \text { via employment; } \\
5 \text { via social contact }\end{array}$ \\
\hline OA & $\begin{array}{l}\text { Older } \\
\text { adults }\end{array}$ & $\begin{array}{l}7 \\
(5) \\
\end{array}$ & $\begin{array}{l}74 \text { years } \\
(53-83)\end{array}$ & $\begin{array}{l}6 \text { White-British; } \\
1 \text { White-Welsh }\end{array}$ & 1 via employment \\
\hline CG & $\begin{array}{l}\text { Community } \\
\text { sample }\end{array}$ & $\begin{array}{l}7 \\
(7)\end{array}$ & $\begin{array}{l}50 \text { years } \\
(34-68)\end{array}$ & $\begin{array}{l}4 \text { White-British; } \\
1 \text { White- } \\
\text { European; } \\
1 \text { White-Irish; } 1 \\
\text { Black-African }\end{array}$ & $\begin{array}{l}3 \text { via employment; } \\
1 \text { via social contact }\end{array}$ \\
\hline
\end{tabular}

